\title{
Design and Development of Time Donation Application
}

\author{
Funation Application \\ [Yerin Jeong, Seonghun Jeong, Hyeonu Kim, Jiamin Ma, Hankyu Lim, Eunju Park*]
}

\begin{abstract}
With the popularization of smart phones, various applications are being developed for information, social, psychological, functional, and entertainment purposes. Furthermore, mobile donation platforms are increasing and various donation applications are appearing. In line with this trend, we designed and developed a donation app that allows users to donate time without financial burden. With the donation application developed in this study, users can donate their time through the one-minute advertisement view and donate their accumulated money to the donation organizations and programs selected by the user. In addition, we have designed a comprehensive funation application by adding comprehensive information and selling functions for donation products sold by various organizations.
\end{abstract}

Keywords-Donation Application, Web Application, Funation, App Inventor, Web, Mobile Application

\section{Introduction}

As smartphone users increase, many applications are being developed and used in various fields for information, social, psychological, functional, and entertainment purposes [1]. Furthermore, donation applications based on mobile apps are increasing, which allows communication at anytime, anywhere, and various donation schemes are emerging [2] [3]. Nowadays, people can practice sharing easily using mobile applications, instead of classical methods of donating cash or goods [4].

As donation methods have become more diverse, there is now a movement to find more interesting donations. Funation, a combination of 'fun' and 'donation', is a new term that means sharing activities in which both donors and beneficiaries can have fun, rather than just giving and receiving donations. A typical example is Ice Bucket Challenge, which has spread rapidly through the social networks during the summer of 2014 [5].

There is a growing interest in donation products that can be donated just by consumption. TOMS Shoes' cause marketing (marketing that links social issues and corporate interests), which offered a pair of shoes to African children for every shoes sold, showed 40 fold increase in sales in three years and 35 million pairs of shoes were donated [6]. Besides, various donation organizations sell various kinds of products including donation bracelets, and some products are so popular that they are easily sold out and difficult to buy. Figure 1 shows donation bracelets, a representative example of donation products.

\footnotetext{
*Corresponding Author

Department of Multimedia Engineering, Andong National University 1375 Gyungdong-ro, Andong-City, Gyeongsangbuk-Do, Republic of
} Korea

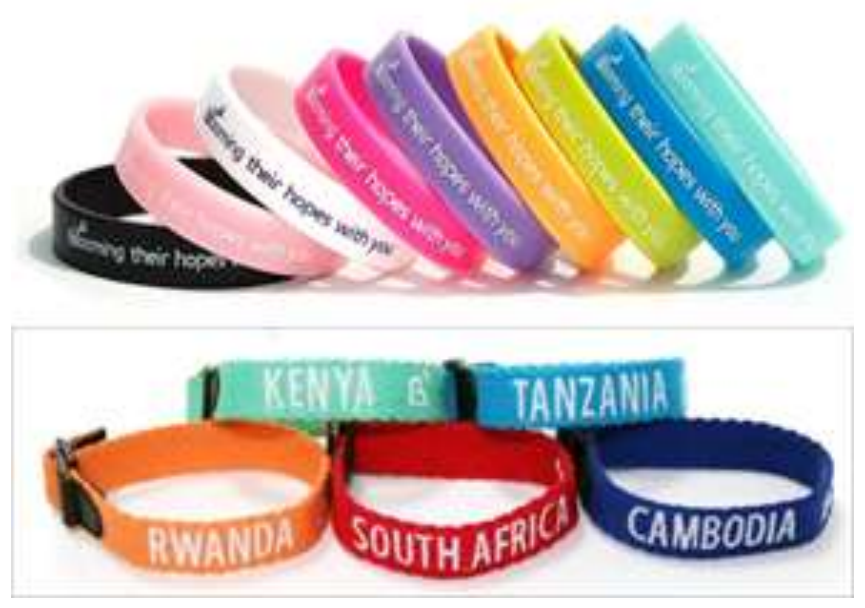

Figure 1. Donation bracelets, a representative example of donation products

In this study, a donation application was designed and developed for smartphones that many people use. With this donation application, people can donate their time by viewing advertisements. Although existing smartphone donation applications have various donation products and sellers, information about them is still insufficient. Therefore, we designed a general funation application with selling features for donation products. This application is expected to increase donations because it can be used anytime, anywhere with no financial burden.

\section{Related Studies}

\section{A. App Inventor}

App Inventor is a program that can be used to develop apps on an Android phone or emulator. An advantage of this program is that there is no need to install a separate program to produce apps because it is done in Google Chrome browser [7]. App Inventor also has its own server, which allows users to save their work and easily manage projects. Anyone who is not a programmer can easily produce applications by using blocks instead of manually writing the code [8].

\section{B. Statistics related to donation}

Figure 2 below is a graph showing changes in donation experience and cash donation rate. According to the 'Social Indicators of Korea 2015' published by the Statistics Korea, $29.9 \%$ of South Koreans have made a donation as of 2015. As a result of the recession, both donation experience and cash donation rate are decreasing from 2011 to 2015 [9]. 
Proc. of The Sixth Intl. Conf. On Advances In Computing, Control And Networking - ACCN 2017

Copyright (C) Institute of Research Engineers and Doctors, USA .All rights reserved.

ISBN: 978-1-63248-117-7 doi: 10.15224/ 978-1-63248-117-7-55

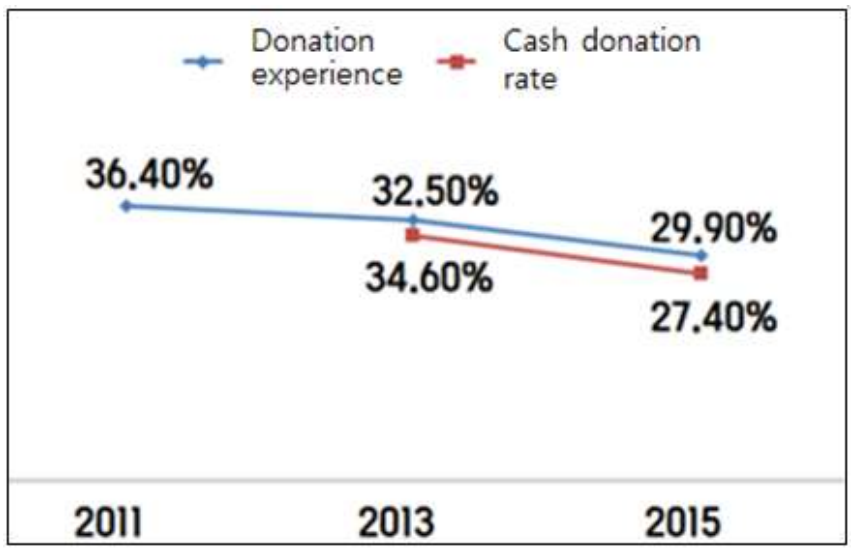

Figure 2.Changing trend graph of donation experience and cash donation rate

Figure 3 shows a bar graph of 'reasons for not donating' which was published at the same time. The answer 'I cannot afford it' is dominantly high at $63.50 \%$ [6].

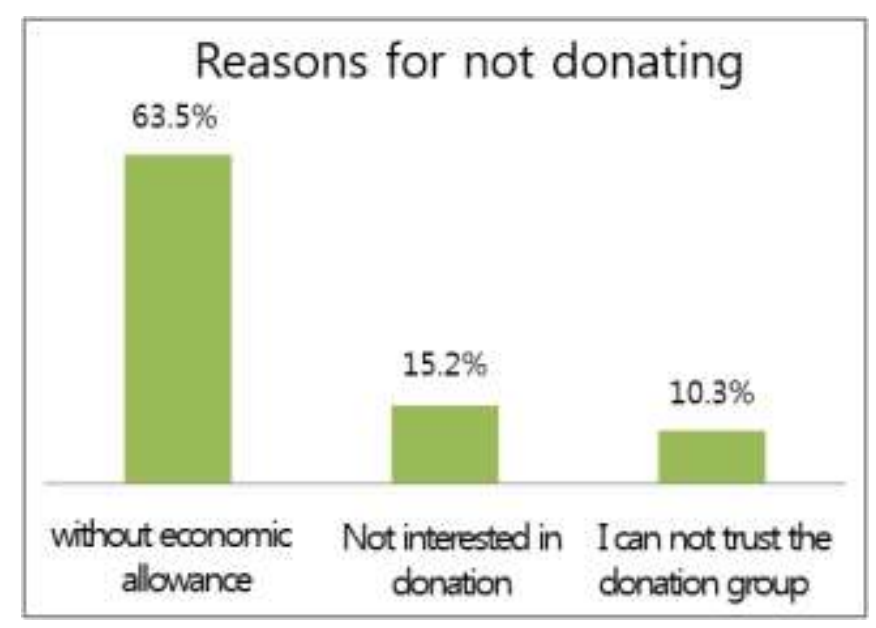

Figure 3. Graph showing reasons for not donating

The above statistics suggests that donation methods with no financial burden are needed and we realized that a donation application that allows people to donate with no financial burden is necessary. With the donation application designed in this study, there is no financial burden because users can donate their time by viewing advertisements and buying donation products that they need. It is expected that the donation application developed in this study would increase participation in donations because it gives no financial burden.

In addition, reflecting the opinion that the donation organizations are unreliable, the proposed application increased reliability by providing more information about the purpose of donations and allowing users to select the donation organization and campaign that they want.

\section{Design and Implementation}

\section{A. Structural Design}

Figure 4 shows the overall system structure of the application developed in this study. After 'Log-in', the main categories consist of '1-minute advertisement view,'
'Donation amount,' 'Donation Products,' and 'Donation Organizations.'

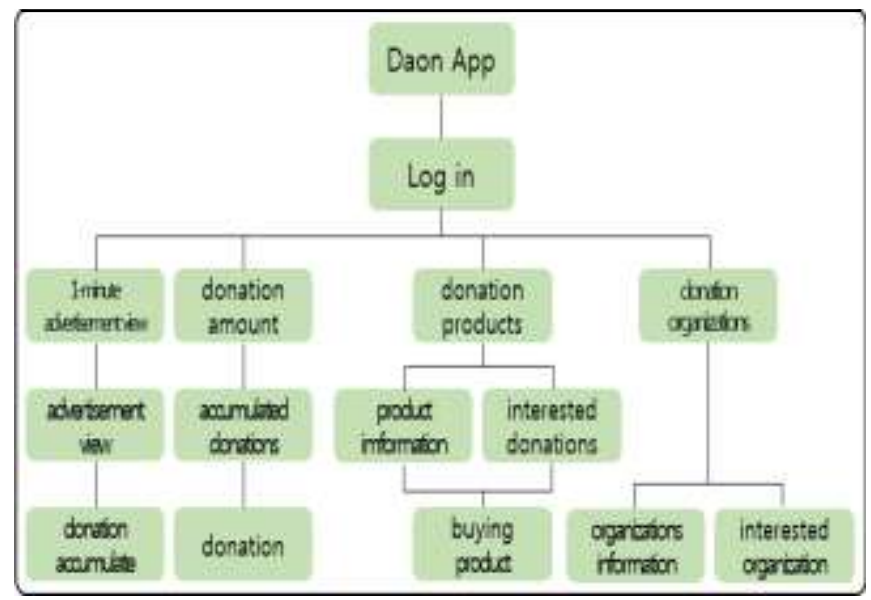

Figure 4. System structure diagram

Figure 5 shows the highest-level data flow diagram (DFD) of the application designed in this study. Users must first join as a member before using the app. All the data including the accumulated donations, purchased donation products that have been purchased, and donation products in the wish lists are stored in the server database together with the log-in information.

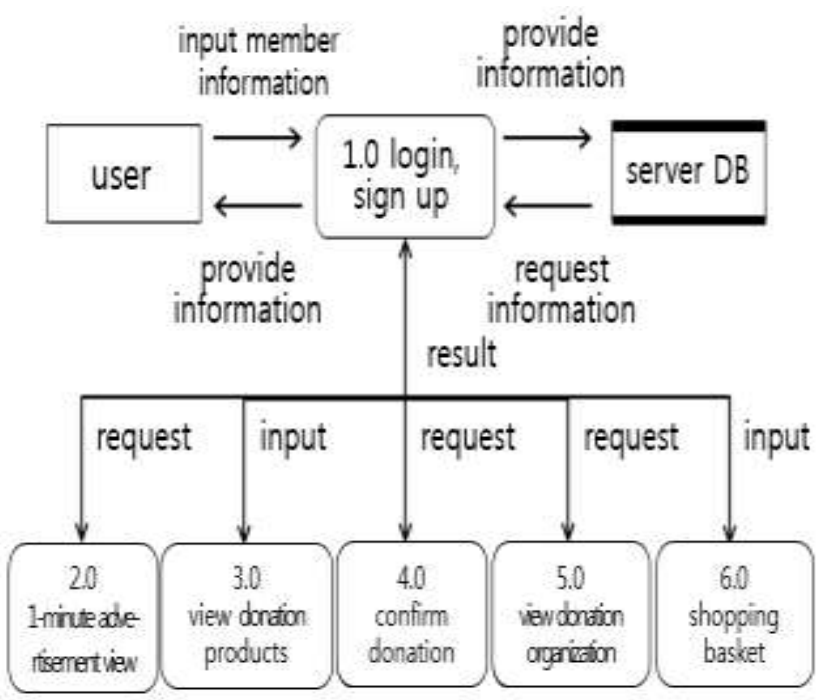

Figure 5. Highest-level data flow diagram

The donation application developed in this study is designed to donate time through the '1-minute advertisement view.' Users must play the videos until the end to donate their time and it is impossible to change the play time in the middle. 'View donation organizations' provides information about various donation organizations and the purpose of the donations. 'View donation products' provides general information about the donation products sold by various organizations and allows users to buy the products. 


\section{B. UI Design}

Figure 6 shows the main page UI of the application, which appears first after users $\log$ in. At the top of the screen, last four donation programs are displayed as thumbnail image buttons. In the middle, image typed buttons are displayed which allow users to move to the list pages of advertisements and products. At the bottom, the companies and donation organizations that have been recently added to the application are displayed to draw interest from users.

\begin{tabular}{||c|c|}
\hline home & menu \\
\hline \multicolumn{1}{|c|}{ donation program } \\
doo0 \\
\hline advertisement \\
\hline related company \\
\hline related donation organizations \\
\hline \multicolumn{2}{|c|}{} \\
\hline
\end{tabular}

Figure 6. Main page UI design

\section{Implementation}

This study focused on UI implementation. Page movement using App Inventor and the accumulation of donations and donation functions based on the database were implemented.

Figures 7 to 9 below show some blocks of the donation application implemented with App Inventor. Figure 7 shows the pop-up window that appears after the video play is finished, which is an App Inventor block for loading points from the database and accumulating them.

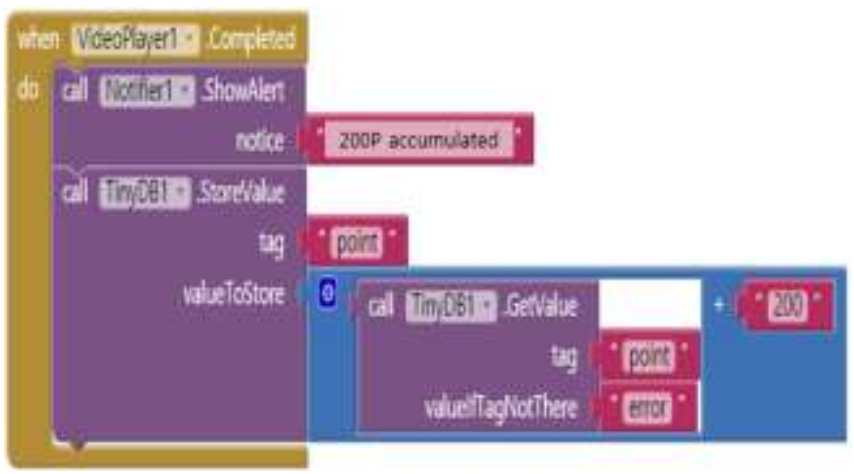

Figure 7. App Inventor block for point accumulation from the database
Figure 8 shows the popup window that appears after making a donation, which is an App Inventor block that loads points from the database and subtract them.

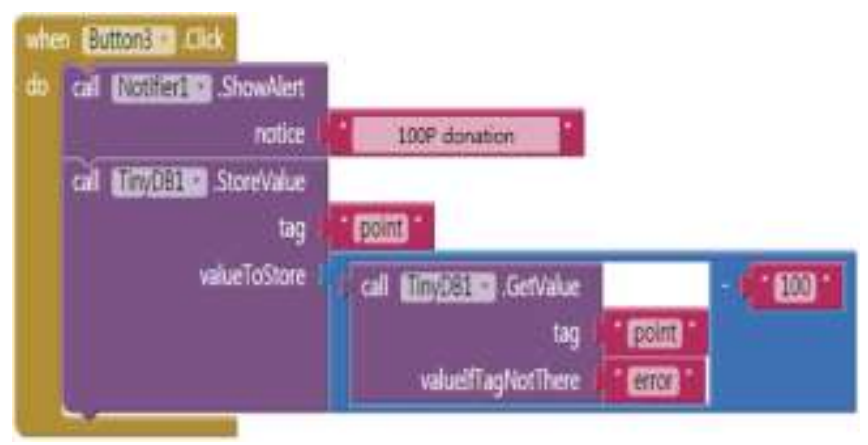

Figure 8. App Inventor block for point subtraction

Figure 9 shows an App Inventor block that loads points from the database and provides accumulated donations.

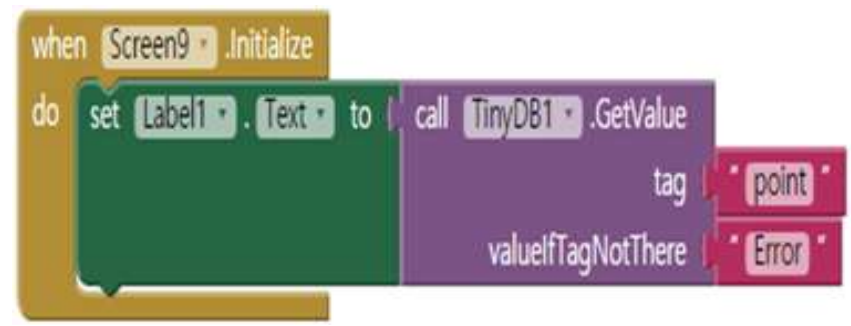

Figure 9. App Inventor block for provision of accumulated donations

Figure 10 shows the initially loaded screen and the login screen that appear when the app is started. The application name 'Daon' means to make everyone feel warm. The UI was designed with red-line colors to give warm feeling.

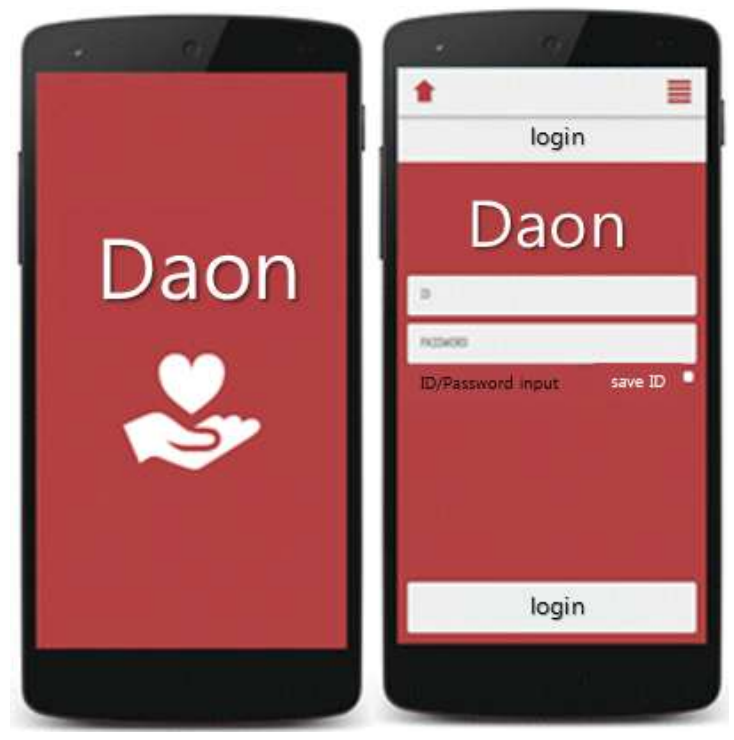

Figure 10. Loading screen and log-in screen

Figure 11 shows the 'main screen' of the application and 'My mileage' view page. Users can select an organization of interest at the bottom of the 'My mileage' view page to go to the page and give donations. 

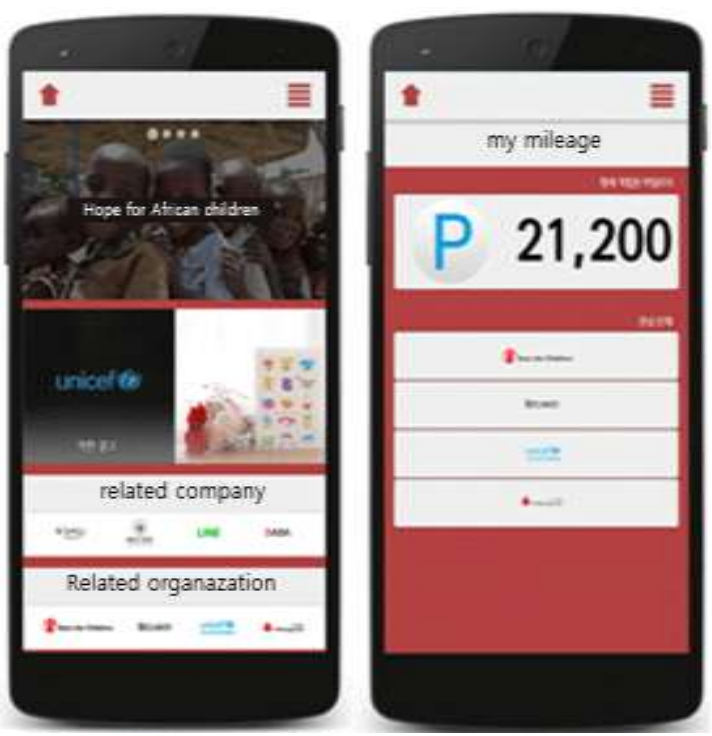

Figure 11. 'Main screen' and 'My mileage' view page

Figure 12 shows the ' 1 -minute advertisement' view page and 'donation' page. After the video play is finished, the message 'Points have been accumulated' pops up and the donation mileages are accumulated. When users donate on the 'donation' page, the corresponding points are subtracted from the accumulated mileages.
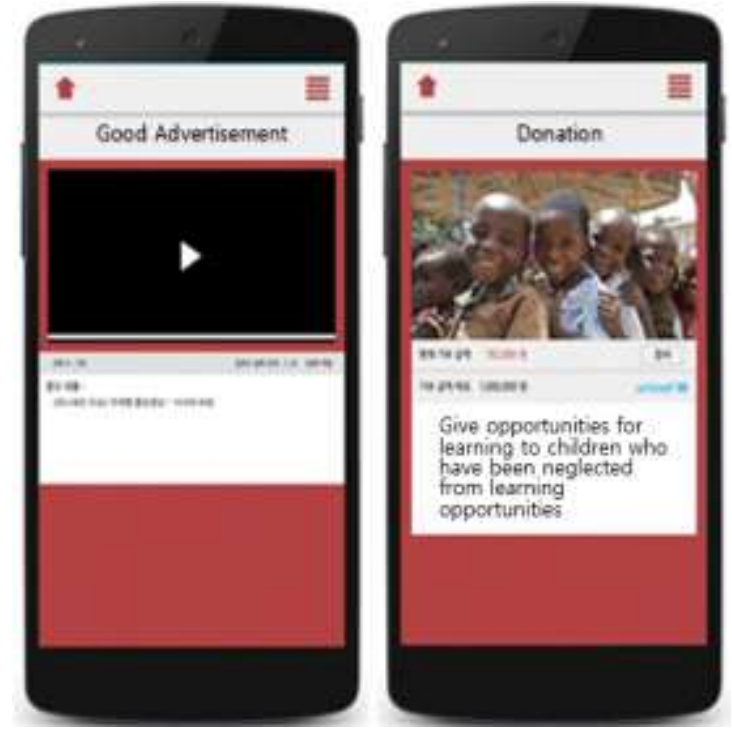

Figure 12. '1-minute advertisement' view page and 'Donate' page

Figure 13 shows the list page of 'donation products' and the detail page of a donation product. After selecting a desired count on the detail page of donation product, users can buy the product or add it to the shopping cart.

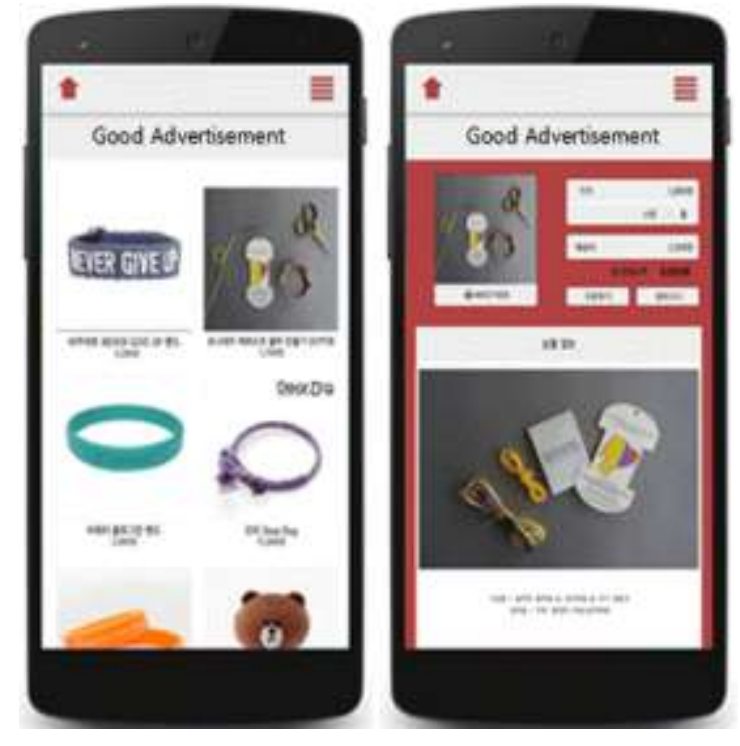

Figure 13. List page of donation products and Detail page

\section{Conclusion}

In this study, a donation application that allows users to donate with their time with no financial burden was designed and developed. With this application, users can donate their time through the ' 1 -minute advertisement view' feature. This is a comprehensive funation application that provides information about various donation products and allows users to buy them. It is expected that using this application will increase people's interest about donation as well as participation in donations. In the future, we will design and develop an application that allows users to accumulate donations through various methods by adding Alarm, To Do List and other features to the application developed in this study.

\section{Acknowledgment}

This work was supported by a grant from 2016 Seoul Accord Project(R0613-16-1148) of MISP(Ministry of Science, ICT and Future Planning) and IITP(Institute for Information and Communication Technology Promotion).

\section{References}

[1] Shen, Xiao Ping, "The Uses and Gratification of Smart Phone Application in Korea and China," Graduate School, Kookmin University of Department of Communication, 2012.

[2] Minji Kim, Byounga Min, Hyeonsik Shin, Seongwook Hwang, Inseong Lee, Jinwoo Kim, "A Case Study of the Mobile Giving Platforms Based on Construal Level Theory: Focused on Bigwalk and Tree Planet," Information systems review, Vol. 17, No. 3, pp.135-157, 2015.

[3] MyoungBeom Chung, IlJu Ko, "Mobile Donation Application of User Participation Base," Journal of the Korea Society of Computer and Information, Vol. 16, No. 11, pp. 113-122, 2011.

[4] YoonHwan Lee, "The effect on continuous usage intention of donation experience through mobile app: Comparison between location based donation app and non-location based donation app," The Graduate School of Advertising and Public Relations Hong-ik University, 2015.

[5] MinBong Kwak, HoeKyung Jung, "Cultural business contents through Social and Funation," Conference Proceedings of the Korea Contents Association 2011 Spring, Vol. 9 No. 1, pp. 145-146, 2011. 
[6] MK Opinion, http://news.mk.co.kr/column/view.php?year=2016\&no $=232963,2016$.

[7] SungJin Hwang, "Effect of Programming Education using App Inventor on Informatics Gifted Elementary Students' Creative Problem Solving Ability and Learning Flow," Graduate School of Korea National University of Education Chung-Buk, KOREA, 2015.

[8] JaeChang Shim, “ Honey App Inventor,” Chaosbook, 2014.

[9] The Korea National Statistical Office, "Social indicators of Korea in 2015,” The Korea National Statistical Office, March 2016.

About Author (s):

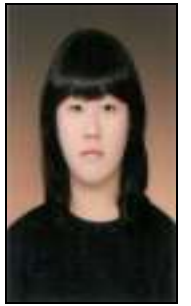

Yerin Jeong, She entered Multimedia Engineering from Andong National University in 2014. She currently is a student at Multimedia Engineering from Andong National University.

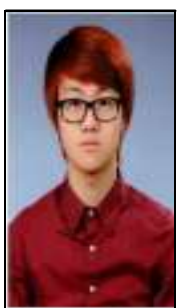

Seonghun Jeong, He entered Multimedia Engineering from Andong National University in 2012. He currently is a student at Multimedia Engineering from Andong National University.

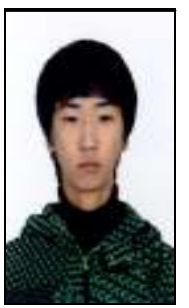

Hyeonu Kim, He entered Multimedia Engineering from Andong National University in 2012. He currently is a student at Multimedia Engineering from Andong National University.

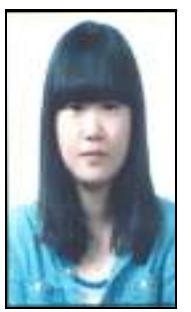

Jiamin Ma, She entered Multimedia Engineering from Andong National University in 2013. She currently is a student at Multimedia Engineering from Andong National University.

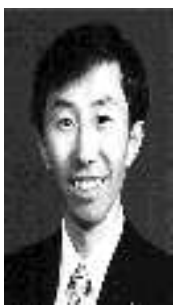

Hankyu Lim, He received the B.S. degree in Electronics Engineering from the Kyungbook National University in 1981. He received the M.S. degree in Computer Engineering from the Yonsei University in 1984. He received the PH. D. degree in Computer Engineering from the Sung Kyun Kwan University in 1997. He is a professor of Andong National University.

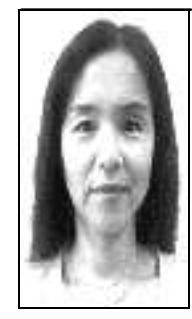

EunJu Park, She received the B.S degree in Computational Statistics from the Andong National University in 1993. She received the M.S. degree in Computer Engineering from the Andong National University in 2001. She received the $\mathrm{Ph}$. D. degree in Information Communication Engineering from Andong National University in 2015. She is a full-time lecturer at Andong National University. 